\title{
Association between Net Ultrafiltration Rate and Renal Recovery among Critically III Adults with Acute Kidney Injury Receiving Continuous Renal Replacement Therapy: An Observational Cohort Study
}

\author{
Raghavan Murugan ${ }^{a, b}$ Samantha J. Kerti ${ }^{b}$ Chung-Chou H. Chang b, c, d \\ Martin Gallagher ${ }^{\mathrm{e}}$ Ary Serpa Neto ${ }^{\mathrm{f}, \mathrm{g}}$ Gilles Clermont $^{\mathrm{b}}$ Claudio Ronco $^{\mathrm{h}}$ \\ Paul M. Palevsky a, c, i John A. Kellum ${ }^{a}$, b Rinaldo Bellomo ${ }^{j}$
}

aDepartment of Critical Care Medicine, The Center for Critical Care Nephrology, CRISMA, University of Pittsburgh School of Medicine, Pittsburgh, PA, USA; 'b Department of Critical Care Medicine, The Clinical Research, Investigation, and Systems Modeling of Acute Illness (CRISMA) Center, University of Pittsburgh School of Medicine, Pittsburgh, PA, USA; ' Department of Medicine, University of Pittsburgh School of Medicine, Pittsburgh, PA, USA; dDepartment of Biostatistics, Graduate School of Public Health, University of Pittsburgh, Pittsburgh, PA, USA; ${ }^{\mathrm{e} T h e}$ George Institute for Global Health and University of Sydney, Sydney, NSW, Australia; 'Department of Critical Care Medicine, Hospital Israelita Albert Einstein, Sao Paulo, Brazil; ${ }^{9}$ Department of Intensive Care, Amsterdam University Medical Centers, Amsterdam, The Netherlands; ${ }^{\text {h}}$ Department of Medicine, International Renal Research Institute of Vicenza and Department of Clinical Nephrology, San Bortolo Hospital, University of Padova, Vicenza, Italy; 'Renal Section, Veterans Affairs Pittsburgh Healthcare System, Pittsburgh, PA, USA; jDepartment of Intensive Care Medicine, Austin Hospital, The University of Melbourne, Parkville, VIC, Australia

\section{Keywords}

Net ultrafiltration $\cdot$ Renal recovery $\cdot$ Competing risk $\cdot$ Acute kidney injury · Kidney replacement therapy

\begin{abstract}
Introduction: Higher net ultrafiltration $\left(\mathrm{UF}_{\mathrm{NET}}\right)$ rates are associated with mortality among critically ill patients with acute kidney injury (AKI) and treated with continuous renal replacement therapy (CRRT). Objective: The aim of the study was to discover whether $U_{\text {NET }}$ rates are associated with renal recovery and independence from renal replacement therapy (RRT). Methods: Retrospective cohort study using data from the Randomized Evaluation of Normal versus Augmented Level of Renal Replacement Therapy trial that en-
\end{abstract} \\ Karger $\stackrel{\text { ' }}{5}$}

rolled 1,433 critically ill patients with $\mathrm{AKI}$ and treated with CRRT between December 2005 and November 2008 across 35 intensive care units in Australia and New Zealand. We examined the association between $U_{\text {NET }}$ rate and time to independence from RRT by day 90 using competing risk regression after accounting for mortality. The UF NET $_{\text {rate was }}$ defined as the volume of fluid removed per hour adjusted for patient body weight. Results and Conclusions: Median age was 67.3 (interquartile range [IQR], 57-76.3) years, $64.4 \%$ were male, median Acute Physiology and Chronic Health Evaluation-III score was 100 (IQR, 84-118), and 634 (44.2\%) died by day 90 . Kidney recovery occurred in 755 patients (52.7\%). Using tertiles of UF $\mathrm{NET}_{\mathrm{NET}}$ rates, 3 groups were defined: high, >1.75; middle, 1.01-1.75; and low, <1.01 mL/kg/h. Proportion of patients alive and independent of RRT among the 
groups were 47.8 versus 57.2 versus $53.0 \% ; p=0.01$. Using competing risk regression, higher $\mathrm{UF}_{\mathrm{NET}}$ rate tertile compared with middle (cause-specific hazard ratio [csHR], 0.79, $95 \% \mathrm{Cl}, 0.66-0.95$; subdistribution hazard ratio [sHR], 0.80, $95 \% \mathrm{Cl}, 0.67-0.97$ ) and lower (csHR, $0.69,95 \% \mathrm{Cl}, 0.56-0.85$; sHR, $0.78,95 \% \mathrm{Cl} 0.64-0.95)$ tertiles were associated with a longer time to independence from RRT. Every $1.0 \mathrm{~mL} / \mathrm{kg} / \mathrm{h}$ increase in rate was associated with a lower probability of kidney recovery (csHR, $0.81,95 \% \mathrm{Cl}, 0.74-0.89$; and sHR, 0.87 , $95 \% \mathrm{Cl}, 0.80-0.95)$. Using the joint model, longitudinal increases in $\mathrm{UF}_{\mathrm{NET}}$ rates were also associated with a lower renal recovery $(\beta=-0.29, p<0.001)$. UF $\mathrm{NET}_{\mathrm{N} T}$ rates $>1.75 \mathrm{~mL} / \mathrm{kg} / \mathrm{h}$ compared with rates $1.01-1.75$ and $<1.01 \mathrm{~mL} / \mathrm{kg} / \mathrm{h}$ were associated with a longer duration of dependence on RRT. Randomized clinical trials are required to confirm this UF NET $_{\text {rate- }}$ outcome relationship.

(c) 2021 S. Karger AG, Base

\section{Introduction}

Net ultrafiltration $\left(\mathrm{UF}_{\mathrm{NET}}\right)$, defined as the net fluid removal during renal replacement therapy (RRT), has been used in the treatment of fluid overload among critically ill patients with acute kidney injury (AKI) for $>70$ years [1]. Several clinical practice guidelines recommend the use of $\mathrm{UF}_{\mathrm{NET}}$ to remove extracellular fluid volume in order to treat fluid overload $[2,3]$. This recommendation is based on several observational studies, suggesting that fluid removal and negative fluid balance are associated with improved outcomes [4-6]. However, uncertainty exists about the optimal rate of fluid removal in acutely ill patients and its association with outcomes.

Our recent work using the Randomized Evaluation of Normal versus Augmented Level (RENAL) of Renal Replacement Therapy clinical trial cohort of critically ill patients treated with continuous renal replacement therapy (CRRT) suggests that $U_{\mathrm{NET}}$ rates $>1.75 \mathrm{~mL} / \mathrm{kg} / \mathrm{h}$, compared with rates $<1.01 \mathrm{~mL} / \mathrm{kg} / \mathrm{h}$, after controlling for fluid balance, were independently associated with lower survival [7]. These findings were also validated in an independent cohort of patients receiving early $\mathrm{UF}_{\mathrm{NET}}$ during CRRT [8]. However, the association of the $\mathrm{UF}_{\mathrm{NET}}$ rate with another important patient-centered outcome of independence from RRT remains unclear.

Slower $\mathrm{UF}_{\mathrm{NET}}$ rates coupled with fluid infusion may worsen fluid overload and expose patients to renal tissue edema and perpetuate renal dysfunction [9-11], whereas faster $\mathrm{UF}_{\mathrm{NET}}$ rates might be associated with intradialytic hypotension and ischemic renal injury $[12,13]$. Both of these complications might impair renal recovery. For instance, studies in patients with end-stage renal disease and incident hemodialysis suggest that higher ultrafiltration rates are associated with a decline in residual kidney function [14]. Small observational studies in critically ill patients also suggest that higher $\mathrm{UF}_{\mathrm{NET}}$ rates are associated with dependence on RRT $[15,16]$. However, these studies did not account for competing risk between mortality and renal recovery, resulting in potential survivor bias and overestimation of renal recovery [17-19]. The use of conventional statistical methods for the analysis of time to independence from RRT (e.g., Kaplan-Meier estimate and Cox proportional hazard model) will result in biased estimates as these models assume that competing risks are absent $[17,20]$.

Thus, we used 2 different competing risk regression methods that account for competing event of mortality to examine the association of $\mathrm{UF}_{\mathrm{NET}}$ rate with time to independence from RRT in a secondary analysis of the RENAL cohort [21]. We fitted a cause-specific regression model to assess the etiological relationship between higher $\mathrm{UF}_{\mathrm{NET}}$ rate and time to independence from RRT. We also fitted a subdistribution model by Fine and Gray to estimate the prognostic probability of time to independence from RRT at any given time for an individual patient.

\section{Materials and Methods}

The University of Pittsburgh's Human Research Protection Office approved this retrospective cohort study with a waiver of informed consent (PRO17090362). However, written informed consent was obtained in the RENAL trial [21] from the patient or a responsible surrogate utilizing either a priori or delayed consent. For this report, we followed the Strengthening the Reporting of Observational Studies in Epidemiology guideline [22].

\section{Study Population}

The RENAL study was conducted in 35 intensive care units in Australia and New Zealand between December 30, 2005, and November 28,2008 . This secondary analysis was performed between May 31, 2018, and December 13, 2019. The RENAL study was a multicenter randomized trial that compared the efficacy of 2 different intensities of solute control using CRRT in critically ill patients with AKI [21]. In brief, patients were eligible to participate in the study if they were critically ill adults with AKI, were deemed to require CRRT by the clinician, and fulfilled predefined criteria including oliguria, severe organ edema, hyperkalemia, uremia, or severe metabolic acidosis (online suppl. Appendix 1; for all online suppl. material, see www.karger.com/doi/10.1159/000517281). Baseline premorbid serum creatinine was determined based on the most recent documented creatinine 12 months before index hospital admission. 
The presence of clinically significant organ edema was prospectively adjudicated by clinicians before randomization based on radiologically confirmed pulmonary edema or visible or palpable organ edema (cardiac or gastrointestinal) at the surgery [21]. The $\mathrm{UF}_{\mathrm{NET}}$ rate was individualized by clinicians and was performed by decreasing the flow of the replacement fluid and the dialysate in equal proportion so that effluent fluid volume exceeded replacement fluid and dialysate volumes.

\section{Patient and Public Involvement}

Patient and public involvement was not sought for this study using a clinical trial database.

\section{Study Variables}

The primary outcome was time to independence from RRT from study enrollment censored at day 90 . The exposure variable was the $\mathrm{UF}_{\mathrm{NET}}$ rate defined as the volume of net ultrafiltrate removed per hour adjusted for patient body weight in kilograms. The hourly $\mathrm{UF}_{\mathrm{NET}}$ volume was calculated after excluding the dialysate and the replacement fluid volumes from the volume of ultrafiltrate (i.e., $\mathrm{UF}_{\mathrm{NET}}=\mathrm{UF}$ volume - [replacement fluid + dialysate volume]). Subsequently, the rate for the duration of treatment was calculated using the following equation $[7,8,23-25]$ :

$$
\mathrm{UF}_{\mathrm{NET}} \text { rate }(\mathrm{mL} / \mathrm{kg} / \mathrm{h})=\frac{\text { cumulative } \mathrm{UF}_{\mathrm{NET}} \text { volume }(\mathrm{mL})}{\text { weight at study enrollment }(\mathrm{kg}) \times \text { treatment duration }(\mathrm{h})} \text {. }
$$

Daily patient fluid balance was first calculated as the difference between fluid administered (i.e., intravenous fluids, blood products, enteral fluids, dialysate, and replacement fluid) and fluid loss (i.e., dialysis effluent from CRRT, urine output, blood loss, enteral losses, and drain losses). We then excluded $\mathrm{UF}_{\mathrm{NET}}$ volume from the output fluids since the $\mathrm{UF}_{\mathrm{NET}}$ rate was the exposure variable [7, 23]. Daily and cumulative fluid balance data were obtained from study enrollment until death, ICU discharge, or completion of 28 days from enrollment. Incomplete study days were considered full data collection days [5]. Study treatment was discontinued on death, discharge from ICU, or recovery of renal function.

We measured covariates for a risk adjustment model to account for confounding by indication [26, 27] because older, sicker, and hemodynamically unstable patients would be expected to receive a slower rate and patients with organ edema and those requiring mechanical ventilation would be expected to receive a faster rate [7]. These included variables specified a priori based on prior studies $[5,7,23,28]$ using age category; female sex; premorbid estimated glomerular filtration rate (eGFR) based on most recent serum creatinine; duration from ICU admission to study enrollment; severity of illness assessed by Acute Physiology and Chronic Health Evaluation-III score category with score ranging from 0 to 299 with higher score indicating more severe illness in the $24 \mathrm{~h}$ before study enrollment; severity of organ dysfunction assessed by total Sequential Organ Failure Assessment (SOFA) score on a scale of $0-4$ for each organ with higher score indicating more severe organ dysfunction; presence of organ edema, sepsis, and use of mechanical ventilation; daily mean cardiovascular SOFA score during treatment; cumulative fluid balance from enrollment to ICU discharge; duration of RRT in days; source of admission including whether the patient was transferred from an emergency department, hospital ward, operating room after elective or emergency surgery, another hospital, or ICU; hospital type; and hospital region. Race and ethnicity were not reported in the clinical trial.
For patients with unknown premorbid serum creatinine $(n=$ $637,44.4 \%$ ), we used the multivariable imputation by a chained equation method to impute creatinine values using age, sex, and weight as predictors (online suppl. Appendix 2) [7, 29, 30]. We subsequently used the Modification of Diet in Renal Disease equation to determine eGFR using the imputed creatinine [31]. There was no difference in the distribution of imputed and unimputed creatinine and corresponding eGFR values (Fig. A1).

\section{Statistical Analysis}

Primary Analyses

To examine the association between $\mathrm{UF}_{\mathrm{NET}}$ rate and time to independence from RRT, we examined several models because of the nonlinear association of the $\mathrm{UF}_{\mathrm{NET}}$ rate with RRT independence (Fig. A2a, b) and selected tertiles and continuous models due to lower Akaike information criterion. Using tertiles, we stratified $U_{\mathrm{NET}}$ rates into 3 groups based on prior work [7]: (1) low, <1.01 $\mathrm{mL} / \mathrm{kg} / \mathrm{h}$; (2) middle, $1.01-1.75 \mathrm{~mL} / \mathrm{kg} / \mathrm{h}$; and (3) high, $>1.75 \mathrm{~mL} /$ $\mathrm{kg} / \mathrm{h}$. To predict RRT independence across a range of $\mathrm{UF}_{\mathrm{NET}}$ rates, we restricted the cohort to $\mathrm{UF}_{\mathrm{NET}}$ rates of $5 \mathrm{~mL} / \mathrm{kg} / \mathrm{h}$ or less $(n=$ $1,428 ; 99.6 \%)$. Categorical variables are presented as counts and frequencies and compared using the $\chi^{2}$ test, and continuous variables are presented as medians and interquartile ranges and compared using the Wilcoxon rank-sum test. To study the absolute risk of RRT independence while accounting for the competing risk of death, we estimated nonparametric cumulative incidence functions.

To examine the association of $\mathrm{UF}_{\mathrm{NET}}$ rate with time to independence from RRT while accounting for other covariates and competing risk of death, we fitted cause-specific models [19, 32-34]. We estimated cause-specific hazard ratios (csHRs) with 95\% CI from Cox models [33, 35] after assessing proportional hazard assumptions (online suppl. Appendix 3; Fig. A3a, b). In these models, since the competing event of death is treated as a censored observation during follow-up, the number of patients at risk is reduced. Thus, the csHRs calculated using this approach are interpreted as among those patients who have not yet died or recovered renal function.

To determine the individual prognostic probability of renal recovery associated with $\mathrm{UF}_{\mathrm{NET}}$ rate while accounting for covariates and risk of death, we fitted subdistribution models by Fine and Gray $[33,35,36]$ and computed subdistribution hazard ratios (sHRs). In this model, subjects who experience death remain in the risk set and the sHR denotes the instantaneous rate of renal recovery in subjects who are still alive (i.e., who have not yet experienced either death or renal recovery) and also those who have died (online suppl. Appendix 4).

In these models, we used the $\mathrm{UF}_{\mathrm{NET}}$ rate of $<1.01 \mathrm{~mL} / \mathrm{kg} / \mathrm{h}$ as a reference and adjusted for covariates with fixed effects for the region and hospital type to account for nonindependence of $U_{\mathrm{NET}}$ rate across hospitals. Models were fitted using 1,341 patients (93.6\%) after excluding patients with missing covariate data on source of ICU admission $(n=91)$, number of CRRT treatment days $(n=1[0.1 \%])$, mortality $(n=1,[0.1 \%])$, and renal recovery status $(n=1,[0.01 \%])$.

We conducted longitudinal analyses using a joint model to account for the correlation between daily $\mathrm{UF}_{\mathrm{NET}}$ rate and cardiovascular SOFA score over time and its association with time to independence from RRT. We chose joint modeling because it allowed us to simultaneously model associations between $\mathrm{UF}_{\mathrm{NET}}$ rate, changes in $\mathrm{UF}_{\mathrm{NET}}$ rate over time, $\mathrm{UF}_{\mathrm{NET}}$ rate, and time-to-RRT independence in a single unified model while accounting for correlated data (online suppl. Appendix 5) [37, 38]. 


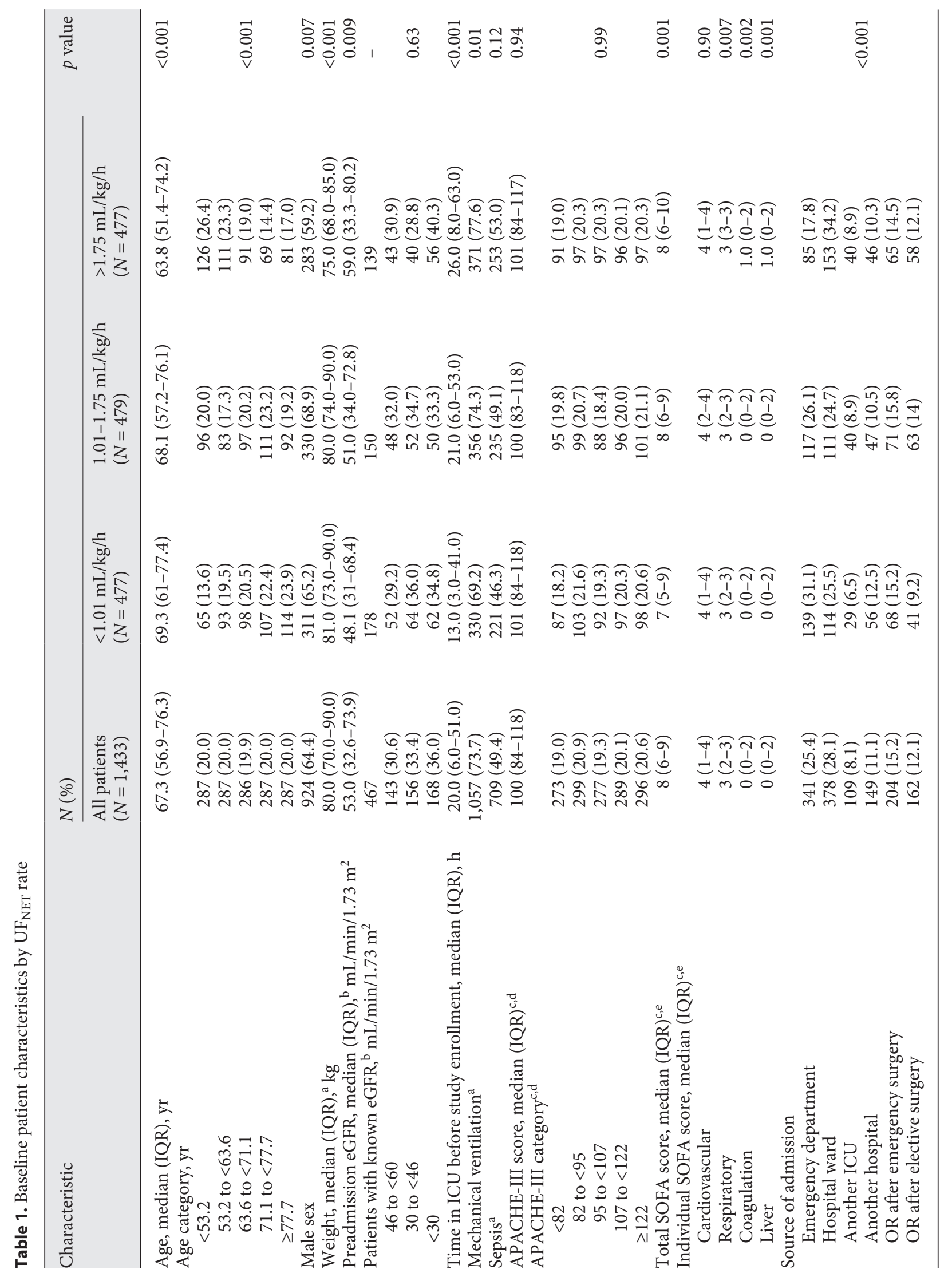




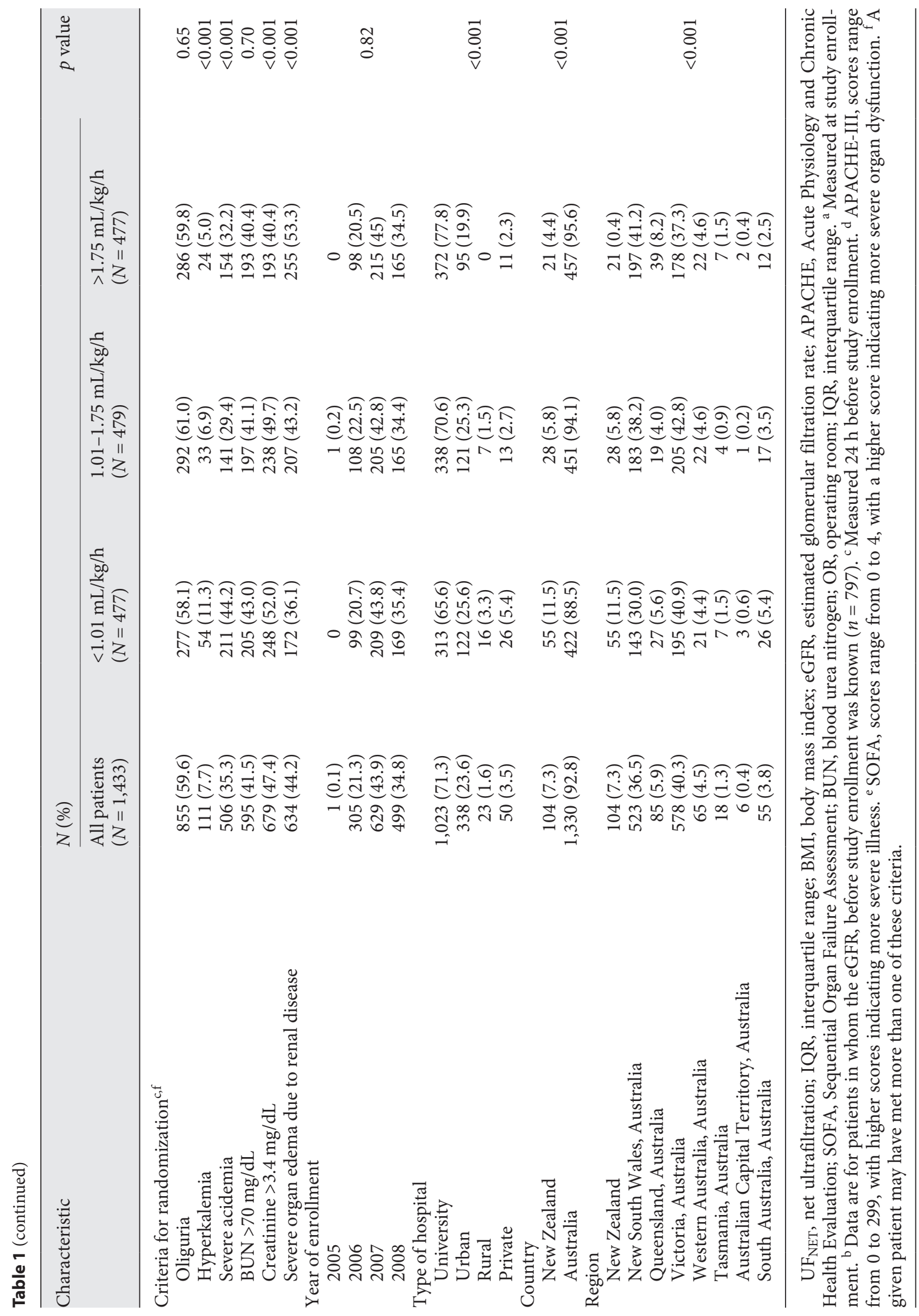


Secondary Analyses

Using cause-specific models, we assessed the robustness of findings in multiple sensitivity and subgroup analyses. First, we restricted the $U_{\mathrm{NET}}$ rate to the first $72 \mathrm{~h}$ of CRRT. Second, we classified patients using a maximum $\mathrm{UF}_{\mathrm{NET}}$ rate. Third, we excluded 92 patients with $U_{\mathrm{NET}}$ rates $<0.01 \mathrm{~mL} / \mathrm{kg} / \mathrm{h}$. Fourth, we included 31 patients with missing treatment duration by assigning a UF $\mathrm{NET}_{\mathrm{N}}$ rate of $0 \mathrm{~mL} / \mathrm{kg} / \mathrm{h}$. Fifth, we adjusted for individual baseline liver, coagulation, and respiratory instead of total SOFA scores. Sixth, we adjusted for the cumulative fluid balance that included UF $_{\text {NET }}$ volume in output fluid calculation. Seventh, we excluded the cumulative fluid balance from the models. Eighth, we stratified based on CRRT for $<3$ and $\geq 3$ days. Ninth, we only fitted models among patients with negative daily fluid balance during ICU stay. Tenth, we matched patients based on propensity scores for receiving UFNET rates $>1.75 \mathrm{~mL} / \mathrm{kg} / \mathrm{h}$ with that of $U_{\mathrm{NET}}$ rates $<1.75 \mathrm{~mL} / \mathrm{kg} / \mathrm{h}$ ( $n=406$ matched pairs).

Using subgroup analyses, we assessed for effect modification with a test for an interaction between $\mathrm{UF}_{\mathrm{NET}}$ rate and patient characteristic in a prespecified subpopulation including patients with and without organ edema, sepsis, premorbid eGFR $<60$ and $\geq 60$ $\mathrm{mL} / \mathrm{min} / 1.73 \mathrm{~m}^{2}$, cardiovascular SOFA score $<3$ and $\geq 3$, and highand low-intensity CRRT. Cause-specific and Fine and Gray models were fitted using SAS 9.4 (SAS Institute, Cary, NC, USA). Joint models were fitted using R 2.14.0 and multiple imputations using MICE command in R 3.4.2. All hypothesis tests were 2-sided, with a significance level of $p<0.05$.

\section{Results}

\section{Patient Characteristics}

Of 1,508 patients enrolled in the RENAL trial, consent was withdrawn by 43 patients. Of the remaining 1,465 patients, we excluded 31 patients for whom the treatment hours for CRRT and 1 patient with missing RRT status (Table A1). Of the 1,433 eligible patients, median (interquartile range [IQR]) age was 67.4 (56.9-76.3) years; body weight was 80.0 (IQR, 70.0-90.0) kg; and 924 patients $(64.5 \%)$ were men (Table 1$)$. Premorbid eGFR was 53.0 (IQR, 32.6-73.8) $\mathrm{mL} / \mathrm{min} / 1.73 \mathrm{~m}^{2}$, the Acute Physiology and Chronic Health Evaluation-III score was 100 (IQR, 84-118), and 634 patients (44.2\%) died. Of the 1,433 patients, 477 patients received $\mathrm{UF}_{\mathrm{NET}}<1.01 \mathrm{~mL} /$ $\mathrm{kg} / \mathrm{h}, 479$ patients received $\mathrm{UF}_{\mathrm{NET}}$ between 1.01 and 1.75 $\mathrm{mL} / \mathrm{kg} / \mathrm{h}$, and 477 patients received $\mathrm{UF}_{\mathrm{NET}}>1.75 \mathrm{~mL} / \mathrm{kg} / \mathrm{h}$ (Table 1).

$\mathrm{UF}_{\mathrm{NET}}$ rates $>1.75 \mathrm{~mL} / \mathrm{kg} / \mathrm{h}$ were associated with young age, female sex, lower body weight, higher eGFR, mechanical ventilation, and longer ICU stay before study enrollment than patients receiving $\mathrm{UF}_{\mathrm{NET}}$ rates between 1.01 and $1.75 \mathrm{~mL} / \mathrm{kg} / \mathrm{h}$ or $<1.01 \mathrm{~mL} / \mathrm{kg} / \mathrm{h}$. Patients with $\mathrm{UF}_{\mathrm{NET}}$ rates $>1.75 \mathrm{~mL} / \mathrm{kg} / \mathrm{h}$ had more severe organ dysfunction, as evidenced by higher median total SOFA score and organ edema at study enrollment. However, the risk of hyperkalemia and metabolic acidosis was lower than patients with $\mathrm{UF}_{\mathrm{NET}}$ rates $1.01-1.75 \mathrm{~mL} / \mathrm{kg} / \mathrm{h}$ and rates $<1.01 \mathrm{~mL} / \mathrm{kg} / \mathrm{h}$. There were also variations in source of admission to the ICU, type of hospital, country, and region (Table 1 ).

Following initiation of CRRT, patients with $\mathrm{UF}_{\mathrm{NET}}$ rates $>1.75 \mathrm{~mL} / \mathrm{kg} / \mathrm{h}$ were associated with having a similar median cardiovascular SOFA score (Table 2) and a longer median duration of treatment with CRRT. Patients receiving $\mathrm{UF}_{\mathrm{NET}}>1.75 \mathrm{~mL} / \mathrm{kg} / \mathrm{h}$ had higher negative median daily and cumulative fluid balances. Median hourly and cumulative $\mathrm{UF}_{\mathrm{NET}}$ volumes were also higher for patients receiving $U \mathrm{UF}_{\mathrm{NET}}>1.75 \mathrm{~mL} / \mathrm{kg} / \mathrm{h}$ for the duration of CRRT. Patients treated with $U_{\text {NET }}$ rates $>1.75 \mathrm{~mL} / \mathrm{kg} / \mathrm{h}$ had a longer duration of mechanical ventilation and RRT, ICU, and hospital length of stay than patients receiving $\mathrm{UF}_{\mathrm{NET}}$ rates between 1.01 and $1.75 \mathrm{~mL} / \mathrm{kg} / \mathrm{h}$ and $<1.01$ $\mathrm{mL} / \mathrm{kg} / \mathrm{h}$. At day 90 , more patients receiving $\mathrm{UF}_{\mathrm{NET}}$ rates $>1.75 \mathrm{~mL} / \mathrm{kg} / \mathrm{h}$, compared with rates $1.01-1.75$, and $<1.01$ $\mathrm{mL} / \mathrm{kg} / \mathrm{h}$ have died ( 48.6 vs. 39.2 vs. $44.9 \% ; p=0.01$ ).

\section{Primary Analyses}

Between day 1 and day 90, 228 patients (47.8\%) treated with $U_{\text {NET }}$ rates $>1.75 \mathrm{~mL} / \mathrm{kg} / \mathrm{h}, 274$ patients $(57.2 \%)$ treated with $\mathrm{UF}_{\mathrm{NET}}$ rates between 1.75 and $1.01 \mathrm{~mL} / \mathrm{kg} / \mathrm{h}$, and 253 patients $(53.0 \%)$ treated with $U_{F_{N E T}}$ rates $<1.01$ $\mathrm{mL} / \mathrm{kg} / \mathrm{h}$ were alive and independent of RRT. UF $\mathrm{NET}_{\mathrm{Nates}}$ $>1.75 \mathrm{~mL} / \mathrm{kg} / \mathrm{h}$ compared with rates $1.01-1.75 \mathrm{~mL} / \mathrm{kg} / \mathrm{h}$ (csHR, 0.79, 95\% CI, 0.66-0.95) and rates $<1.01 \mathrm{~mL} / \mathrm{kg} / \mathrm{h}$ (csHR, 0.69, 95\% CI, 0.56-0.85; Fig. 1a, 2; Table A2) were associated with a longer time to independence from RRT. There was no difference in renal recovery between $\mathrm{UF}_{\mathrm{NET}}$ rate $1.01-1.75 \mathrm{~mL} / \mathrm{kg} / \mathrm{h}$ group compared with $\mathrm{UF}_{\mathrm{NET}}$ rate $<1.01 \mathrm{~mL} / \mathrm{kg} / \mathrm{h}$ group (csHR, 0.87, 95\% CI, 0.72-1.06).

Every $1.0 \mathrm{~mL} / \mathrm{kg} / \mathrm{h}$ increase in rate was associated with $19 \%$ lower probability renal recovery (csHR, 0.81, 95\% CI, 0.74-0.89; Fig. 2; Table A3; Fig. A2b), and this association was not modified by organ edema strata, sepsis, eGFR $>60$, mean cardiovascular SOFA score $\geq 3$, or highintensity CRRT. Using a joint model, a longitudinal increase and a variation in the $\mathrm{UF}_{\mathrm{NET}}$ rate over time were associated with a longer time to independence from RRT $(\beta=-0.29, p<0.001)$. Of the subgroup of survivors at day $90(n=799), \mathrm{UF}_{\mathrm{NET}}$ rate $>1.75 \mathrm{~mL} / \mathrm{kg} / \mathrm{h}$, compared with $\mathrm{UF}_{\mathrm{NET}}$ rate $<1.01 \mathrm{~mL} / \mathrm{kg} / \mathrm{h}$, was also associated with a longer time to RRT independence (adjusted HR, 0.80, 95\% CI, 0.72-0.88; $p<0.001)$.

Using the Fine and Gray model, $\mathrm{UF}_{\mathrm{NET}}$ rates $>1.75$ $\mathrm{mL} / \mathrm{kg} / \mathrm{h}$ compared with $\mathrm{UF}_{\mathrm{NET}}$ rates $1.01-1.75 \mathrm{~mL} / \mathrm{kg} / \mathrm{h}$ 


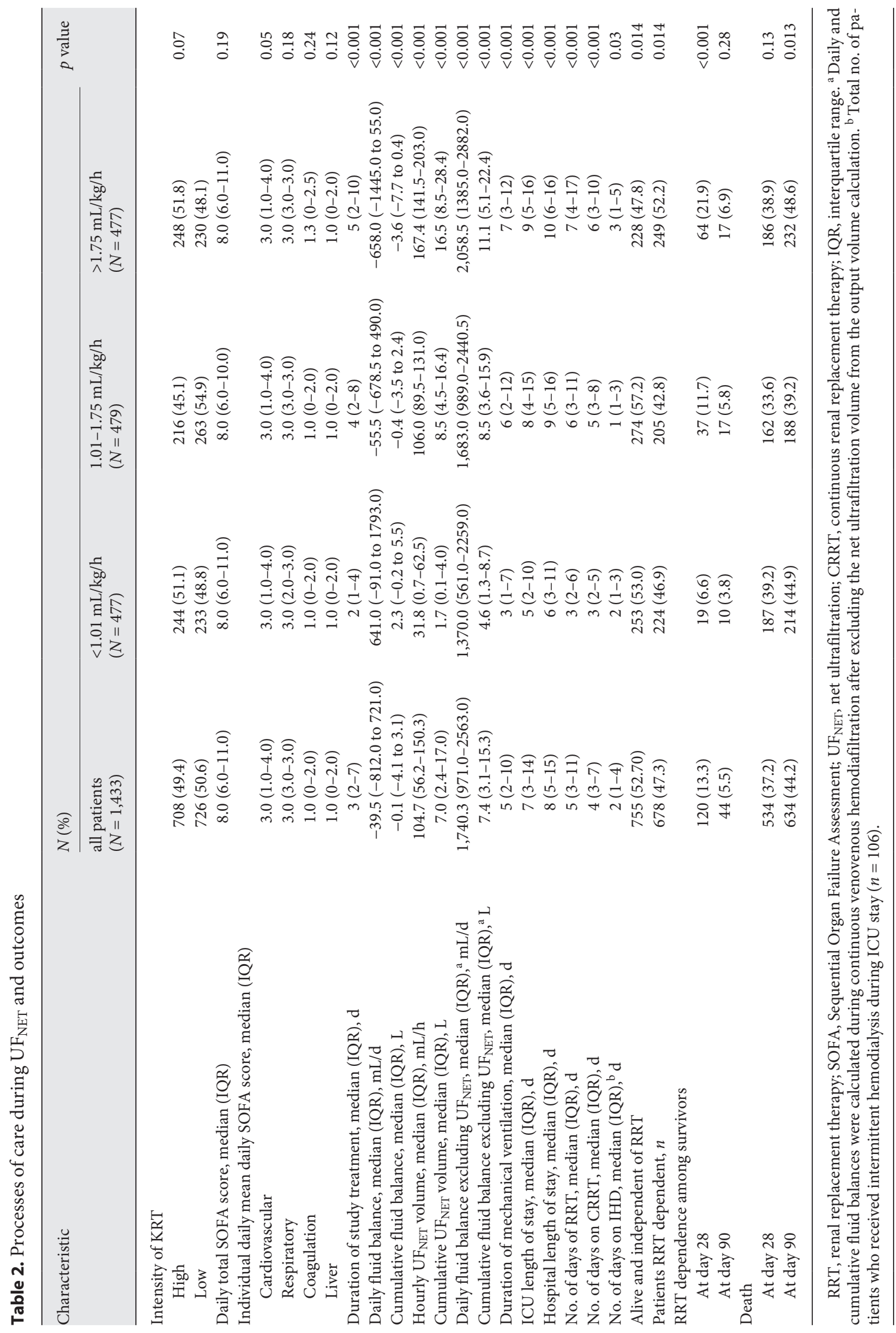




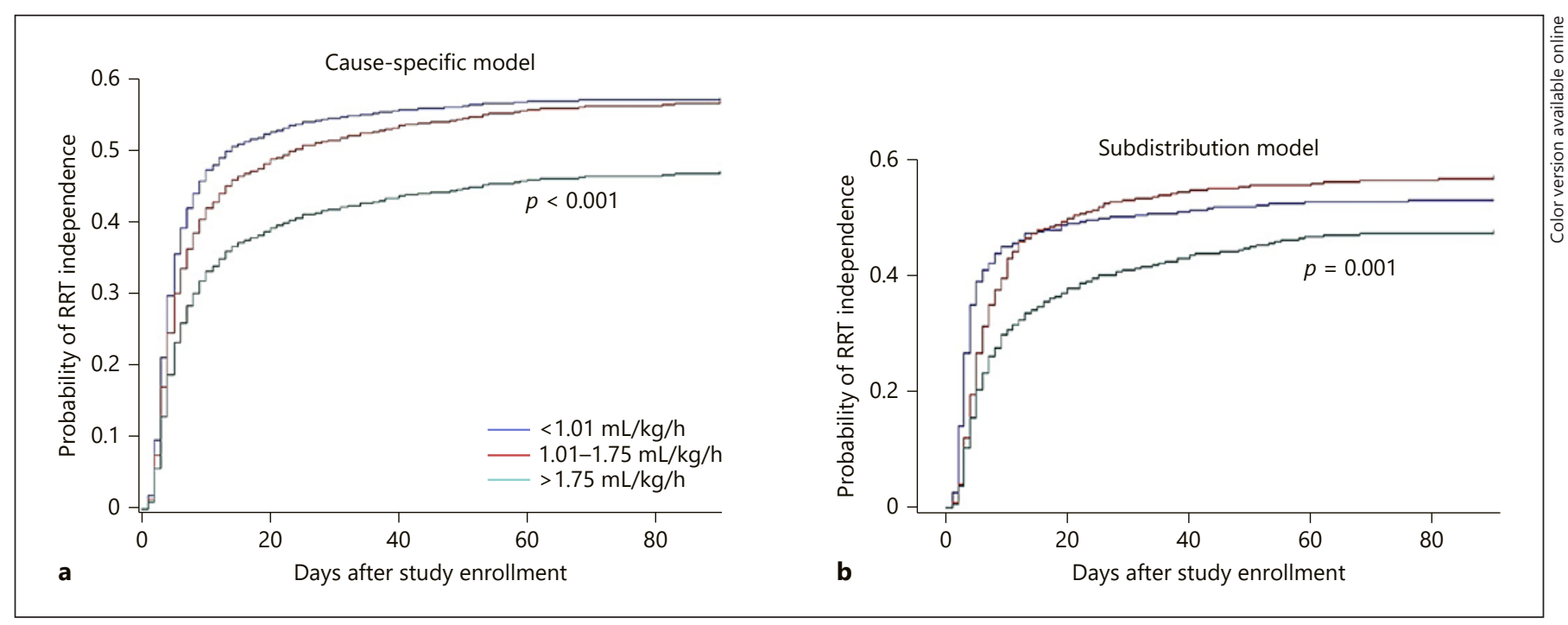

Fig. 1. Time to independence from renal replacement therapy by $\mathrm{UF}_{\mathrm{NET}}$ rate. Shown are cumulative incidence probability of time to independence from RRT by $\mathrm{UF}_{\mathrm{NET}}$ rate estimated from cause-specific (a) and subdistribution models (b). Renal recovery was lowest

for $\mathrm{UF}_{\mathrm{NET}}$ rates $>1.75 \mathrm{~mL} / \mathrm{kg} / \mathrm{h}$ when compared with rates between 1.01 and $1.75 \mathrm{~mL} / \mathrm{kg} / \mathrm{h}$ and rates $<1.01 \mathrm{~mL} / \mathrm{kg} / \mathrm{h}$. UF $\mathrm{NET}_{\mathrm{N}}$, net ultrafiltration; RRT, renal replacement therapy.

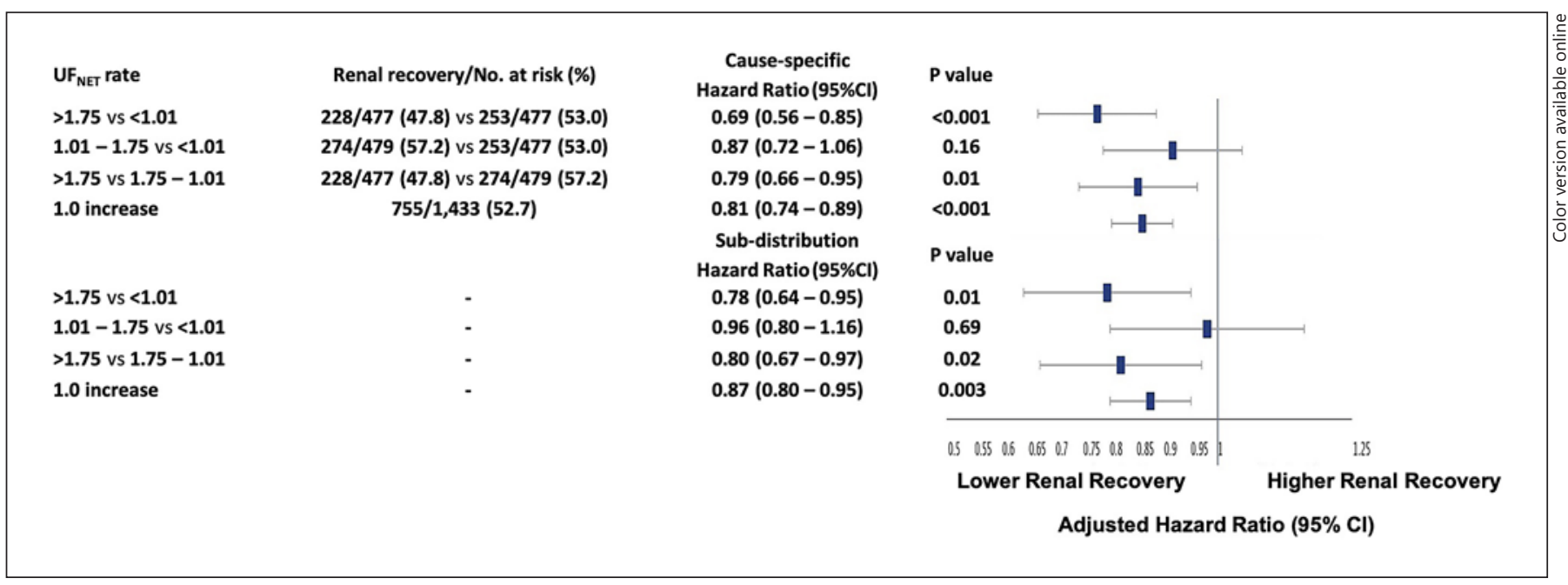

Fig. 2. Risk-adjusted hazard ratios for the association of $U_{F}$ NET rate with time to independence from renal replacement therapy. The embedded table reports the total number of patients who were independent from renal replacement therapy by day 90 and risk adjustment with 95\% CI from cause-specific models and Fine and Gray models. A csHR $<1$ suggests that at any given time, higher $U_{\text {NET }}$ rates, compared with lower $U_{\text {NET }}$ rates, are associated with a longer time to independence from renal replacement therapy among patients who were alive at that time. A sHR $<1$ suggests that higher $U_{\mathrm{NET}}$ rates, compared with lower $\mathrm{UF}_{\mathrm{NET}}$ rates, are associated with a longer time to independence from renal replacement therapy among patients who were alive or those who have not yet recovered renal function at any given time. Variables in the riskadjusted models include age category; female sex; premorbid eGFR; duration from ICU admission to study enrollment;
APACHE-III category in the $24 \mathrm{~h}$ before study enrollment; total SOFA score at study enrollment; presence of organ edema, sepsis, and use of mechanical ventilation at enrollment; daily mean cardiovascular SOFA score during treatment with CRRT; cumulative daily fluid balance from study enrollment to ICU discharge; duration of renal replacement therapy; source of admission including whether the patient was transferred to the ICU from an emergency department, hospital ward, operating room after elective or emergency surgery, another hospital, or ICU; hospital type; and hospital region. Models were fitted in 1,341 patients with complete data. $U_{\mathrm{NET}}$, net ultrafiltration; SOFA, Sequential Organ Failure Assessment; APACHE, Acute Physiology and Chronic Health Evaluation; CRRT, continuous renal replacement therapy; eGFR, estimated glomerular filtration rate; csHR, cause-specific hazard ratio; $\mathrm{sHR}$, subdistribution hazard ratio. 


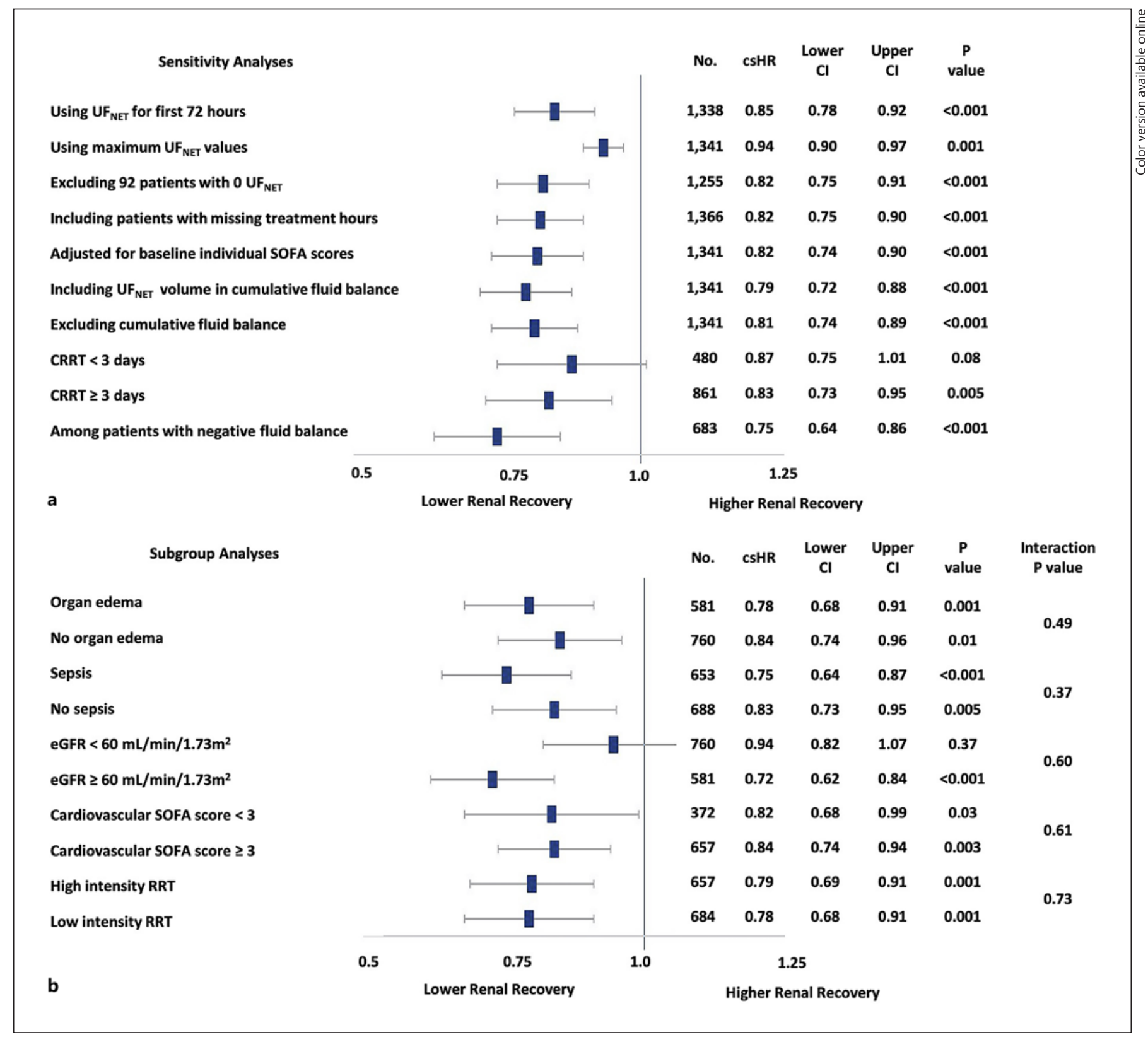

Fig. 3. Sensitivity and subgroup analyses for the association of UFNET rate with time to independence from renal replacement therapy. Forrest plots showing sensitivity (a) and subgroup analysis (b) of association of $\mathrm{UF}_{\mathrm{NET}}$ rate with risk-adjusted renal recovery along with $95 \%$ CI from the cause-specific models. UF $_{\mathrm{NET}}$, net ul- trafiltration; SOFA, Sequential Organ Failure Assessment; eGFR, estimated glomerular filtration rate; CRRT, continuous renal replacement therapy; RRT, renal replacement therapy; csHR, causespecific hazard ratio.
(sHR, 0.80, 95\% CI, 0.67-0.97) and $\mathrm{UF}_{\mathrm{NET}}$ rates $<1.01$ $\mathrm{mL} / \mathrm{kg} / \mathrm{h}$ (sHR, 0.78, 95\% CI, 0.64-0.95; Table A4) were also associated with a longer time to independence from RRT (Fig. 1b, 2). However, there was no difference in renal recovery between $U_{\mathrm{NET}}$ rate $1.01-1.75 \mathrm{~mL} / \mathrm{kg} / \mathrm{h}$ group compared with $\mathrm{UF}_{\mathrm{NET}}$ rate $<1.01 \mathrm{~mL} / \mathrm{kg} / \mathrm{h}$ group
(sHR, 0.96, 95\% CI, 0.80-1.16). Every $1.0 \mathrm{~mL} / \mathrm{kg} / \mathrm{h}$ increase in rate was associated with $13 \%$ lower probability of renal recovery (sHR, 0.87, 95\% CI, 0.80-0.95; Table A5). Our findings did not change when adjusted for daily fluid balance instead of cumulative fluid balance in the models (Table A6). 


\section{Secondary Analyses}

Every $1.0 \mathrm{~mL} / \mathrm{kg} / \mathrm{h}$ increase in the $\mathrm{UF}_{\mathrm{NET}}$ rate was associated with a longer time to independence from RRT when the $\mathrm{UF}_{\mathrm{NET}}$ rate calculation was restricted to first 72 h of CRRT (csHR, 0.85, 95\% CI: 0.78-0.92; Fig. 3a; Table A7), using maximum $\mathrm{UF}_{\mathrm{NET}}$ values (csHR, 0.94, 95\% CI, 0.90-0.97), after excluding 92 patients with $\mathrm{UF}_{\mathrm{NET}}$ rate $<0.01 \mathrm{~mL} / \mathrm{kg} / \mathrm{h}$ (csHR, 0.82, 95\% CI, 0.75-0.91), and after including the 31 patients with missing treatment hours and assigning a $\mathrm{UF}_{\mathrm{NET}}$ rate of $0 \mathrm{~mL} / \mathrm{kg} / \mathrm{h}$ (csHR, 0.82, 95\% CI, 0.75-0.90). An increasing $\mathrm{UF}_{\mathrm{NET}}$ rate was also associated with a longer time to independence from RRT after adjusting for baseline individual SOFA scores (csHR, $0.82,95 \% \mathrm{CI}, 0.74-0.90$ ), cumulative fluid balance including $\mathrm{UF}_{\mathrm{NET}}$ volume (csHR, 0.79, 95\% CI, 0.72-0.88), excluding cumulative fluid balance (csHR, $0.81,95 \% \mathrm{CI}$, 0.74-0.89), including only patients treated with CRRT for $\geq 3$ days (csHR, 0.83 , 95\% CI: 0.73-0.95) and among those with negative fluid balance (csHR, 0.75, 95\% CI, 0.640.86 ), and following propensity score matching (csHR, $0.76,95 \%$ CI, 0.63-0.92).

Using subgroup analyses, an increase in $\mathrm{UF}_{\mathrm{NET}}$ rate was associated with a longer time to independence from RRT among patients with (csHR, 0.78, 95\% CI, 0.68-0.91; Fig. 3b; Table A8) and without organ edema (csHR, 0.84, 95\% CI, 0.74-0.96); with (csHR, 0.75, 95\% CI, 0.64-0.87) and without sepsis (csHR, 0.83, 95\% CI, 0.73-0.95); and eGFR $\geq 60 \mathrm{~mL} / \mathrm{min} / 1.73 \mathrm{~m}^{2}$ (csHR, 0.72, 95\% CI, $0.62-$ 0.84). A higher $\mathrm{UF}_{\mathrm{NET}}$ rate was associated with a lower probability of RRT independence among patients with cardiovascular SOFA score $<3$ (csHR, 0.82, 95\% CI, 0.680.99 ) and $\geq 3$ (csHR, 0.84, 95\% CI, 0.74-0.94) and high(csHR, 0.79, 95\% CI, 0.69-0.91) and low-intensity solute dosing (csHR, 0.78, 95\% CI, 0.68-0.91).

\section{Discussion/Conclusion}

In these secondary analyses of a multicenter cohort of critically ill patients with AKI treated with CRRT, we found that $\mathrm{UF}_{\mathrm{NET}}$ rates $>1.75 \mathrm{~mL} / \mathrm{kg} / \mathrm{h}$, compared with $\mathrm{UF}_{\mathrm{NET}}$ rates $<1.01 \mathrm{~mL} / \mathrm{kg} / \mathrm{h}$, and rates $1.01-1.75 \mathrm{~mL} / \mathrm{kg} / \mathrm{h}$ were independently associated with a longer time to independence from RRT after accounting for competing risk of death and patient fluid balance. These findings are aligned with our prior work, showing an association of $\mathrm{UF}_{\mathrm{NET}}$ rates $>1.75 \mathrm{~mL} / \mathrm{kg} / \mathrm{h}$ with lower survival $[7,8]$ and suggesting that higher $\mathrm{UF}_{\mathrm{NET}}$ rates per se independent of fluid balance are associated with a lower renal recovery. In our study, even though $44.3 \%$ of patients had died and
RRT dependence among survivors at day 90 was low (5.5\%), our findings suggest that a greater proportion of patients receiving $U_{\mathrm{NET}}$ rates $>1.75 \mathrm{~mL} / \mathrm{kg} / \mathrm{h}$ do not recover kidney function before death.

It is important to note that fluid balance and fluid removal rate, though inter-related, are not synonymous with each other. While the fluid balance is associated with patient outcomes in several studies [5, 39, 40], our study suggests that the fluid removal rate, independent of fluid balance, is an emerging and important parameter, that is, amenable to intervention. Although randomly assigning patients to fluid removal versus no fluid removal may not be feasible, future studies could examine the effects of restrictive versus liberal rates or range of $\mathrm{UF}_{\mathrm{NET}}$ rates on organ function and patient outcomes independent of fluid balance.

A major strength of our study was that fluid overload in the RENAL trial was prospectively adjudicated by clinicians based on visceral organ edema, and the daily fluid balance data were also prospectively collected. Since both of these variables were adjusted in the models, our findings were not confounded by the presence of greater severity of fluid overload in the higher $\mathrm{UF}_{\mathrm{NET}}$ rate group. In clinical practice, since the $\mathrm{UF}_{\mathrm{NET}}$ rates are titrated based on hemodynamics, we also fitted the joint model to account for the longitudinal changes and variations in $\mathrm{UF}_{\mathrm{NET}}$ rate over time as well as correlation between $\mathrm{UF}_{\mathrm{NET}}$ rate and hemodynamics, and their association with RRT dependence. This analysis also suggested that higher rates are associated with a longer time to independence from RRT.

In our previous work, using a cohort of critically ill patients with $>5 \%$ fluid overload, we also found that UFNET rates $<20 \mathrm{~mL} / \mathrm{kg} /$ day (or $<0.83 \mathrm{~mL} / \mathrm{kg} / \mathrm{h}$ ) compared with $U_{\text {NET }}$ rates $\geq 25 \mathrm{~mL} / \mathrm{kg} /$ day were associated with increased mortality and a trend toward higher dependence on RRT [23]. This finding suggests that extremely slower rates of fluid removal among patients with fluid overload may also be associated with nonrecovery of renal function and mortality. In a prior analysis using the RENAL cohort, survivors had a negative fluid balance compared with a positive fluid balance in nonsurvivors [21]. However, in the current analysis, higher $\mathrm{UF}_{\mathrm{NET}}$ rates were associated with higher daily and cumulative negative fluid balance and yet were independently associated with nonrecovery and mortality when the fluid balance was adjusted in the models. These observations suggest that higher $\mathrm{UF}_{\mathrm{NET}}$ rates independent of fluid balance are associated with a lower renal recovery $[41,42]$.

There are several plausible biological mechanisms of association between higher $\mathrm{UF}_{\mathrm{NET}}$ rates and decreased re- 
nal recovery. Faster ultrafiltration rates have been associated with intradialytic hypotension [43]; ischemic injury to the heart [44], brain [45], GI tract [46], and kidneys [13]; and mortality in several observational studies among patients with end-stage renal disease treated with hemodialysis [47-50]. Among patients with established hemodialysis for at least 3 months who had low residual kidney function, one study using computed tomography perfusion found decreased kidney perfusion and increased number of stunning myocardial segments, both of which were associated with higher mean $\mathrm{UF}_{\mathrm{NET}}$ rates [13]. Supporting these findings is the observation that residual kidney function declines faster among patients treated with hemodialysis in whom higher $\mathrm{UF}_{\mathrm{NET}}$ rates are used compared with peritoneal dialysis $[51,52]$.

Our study also has several limitations. First, being an observational study, our findings do not prove causality between $\mathrm{UF}_{\mathrm{NET}}$ rates and renal recovery but are only hypothesis generating. Since the association between higher $\mathrm{UF}_{\mathrm{NET}}$ rates and lower renal recovery may represent residual confounding due to unmeasured risk factors, our study findings must be interpreted with caution. Nevertheless, our findings persisted in several sensitivity analyses under various assumptions and support the primary analyses. Second, data on race, comorbid conditions, and ultrafiltration treatment during hemodialysis were unavailable and might confound the assessment of renal recovery. Third, there were 31 patients with missing treatment hours; however, including these patients in the analysis did not change the results.

Fourth, the precise fluid balance before the initiation of CRRT was unavailable, a limitation that was addressed using the prospectively adjudicated organ edema variable by clinicians as a surrogate for severity of fluid overload. Fifth, since the RENAL trial was conducted between 2005 and 2008, it is possible that care practices for volume management may have changed, although more recent studies indicate a wide variation in rates of fluid removal and variation across geographic regions [53, 54]. Sixth, we did not measure actual prescribed $\mathrm{UF}_{\mathrm{NET}}$ rates. Thus, it is possible that clinician factors (e.g., higher patientnurse staffing ratio) associated with a mismatch between prescribed-delivered $\mathrm{UF}_{\mathrm{NET}}$ rates might have impacted renal recovery. Seventh, we did not distinguish between removal of obligatory fluids administered (i.e., antibiotics and parenteral nutrition) versus removal of extracellular volume. Thus, it is not possible to distinguish whether the association of $\mathrm{UF}_{\mathrm{NET}}$ rate on outcomes is due to removal of patient extracellular volume or obligatory fluid volumes.

Net Ultrafiltration Rate and Renal Recovery
Eighth, in our study, the $\mathrm{UF}_{\mathrm{NET}}$ rate calculation is based on the machine fluid removal rate and does not necessarily reflect the patient fluid balance. For instance, $100 \mathrm{~mL} / \mathrm{h}$ fluid removal does not necessarily reflect that the patient is net negative $100 \mathrm{~mL} / \mathrm{h}$ since the patient fluid balance depends on simultaneous fluid infusion and fluid loss at any given time. Given these limitations, the risk of nonrecovery associated with higher $\mathrm{UF}_{\mathrm{NET}}$ rates might be smaller than measured in this study.

Among critically ill patients receiving CRRT, $\mathrm{UF}_{\mathrm{NET}}$ rates beyond $1.75 \mathrm{~mL} / \mathrm{kg} / \mathrm{h}$ compared with $\mathrm{UF}_{\mathrm{NET}}$ rates $<1.01$ and $1.01-1.75 \mathrm{~mL} / \mathrm{kg} / \mathrm{h}$ were associated with a longer duration of dependence on RRT after accounting for competing risk of death. Although this study design does not exclude the possibility of residual confounding due to unmeasured risk factors, it provides the rationale for the design of randomized controlled trials comparing conservative with liberal $U_{\mathrm{NET}}$ rates in critically ill patients and examining its association with renal outcomes.

\section{Acknowledgements}

We thank the study participants of the Randomized Evaluation of Normal versus Augmented Level (RENAL) of Renal Replacement Therapy clinical trial, the RENAL study investigators, and the George Institute for Global Health for providing the study data. We also thank the Biostatistics and Data Management Core (BDMC) of the Clinical Research, Investigation, Systems Modelling of Acute Illness (CRISMA) Center for conducting data analysis. The RENAL trial was performed by the RENAL study investigators in collaboration with the Australian and New Zealand Intensive Care Society Clinical Trials Group and the George Institute for Global Health. This manuscript was not prepared in collaboration with all of the RENAL study investigators and does not necessarily reflect the opinions or views of the RENAL study investigators, the George Institute, or the Australian and New Zealand Intensive Care Society.

\section{Statement of Ethics}

The University of Pittsburgh's Human Research Protection Office approved this retrospective cohort study with a waiver of informed consent (PRO17090362). However, written informed consent was obtained in the RENAL trial [21] from the patient or a responsible surrogate utilizing either a priori or delayed consent.

\section{Conflict of Interest Statement}

Dr. Murugan reported receiving grants and personal fees from La Jolla Inc.; grants from Bioporto, Inc. and the National Institute of Diabetes and Digestive and Renal Diseases; and personal fees 
from Beckman Coulter and AM Pharma, Inc., outside the submitted work. Dr. Chang reported receiving grants from the National Institutes of Health during the conduct of the study. Dr. Gallagher reported receiving speaking fees from Amgen outside the submitted work. Dr. Clermont reported receiving personal fees from UpToDate and grants from the National Institutes of Health and the National Science Foundation outside the submitted work. Dr. Ronco reported receiving consulting fees or participating in advisory boards in the last 3 years for ASAHI, Astute, Baxter, Biomerieux, B. Braun, Cytosorbents, ESTOR, FMC, GE, Jafron, Medtronic, and Toray. Dr. Palevsky reported receiving personal fees from Novartis, GE Healthcare, HealthSpan Dx, and Baxter International and grants from Dascena outside the submitted work. Dr. Kellum reported receiving personal fees from NxStage and grants and personal fees from Baxter International during the conduct of the study. Dr. Bellomo reported receiving grants from Baxter International outside the submitted work.

\section{Funding Sources}

Partial support for this work was provided from the National Institute of Diabetes and Digestive and Renal Diseases (5R01DK106256).

\section{Author Contributions}

Dr. Murugan and Ms. Kerti had full access to all of the data in the study and take responsibility for the integrity of the data and the accuracy of the data analysis. Study concept and design: Murugan and Bellomo. Acquisition of data: Bellomo and Gallagher. Analysis and interpretation of data: Kerti, Chang, Murugan, Clermont, Palevsky, Bellomo, Kellum, Gallagher, and Serpa Neto. Drafting of the manuscript: Murugan. Critical revision of the manuscript for important intellectual content: Kellum, Bellomo, Palevsky, Clermont, Murugan, Chang, Kerti, Gallagher, Serpa Neto, and Ronco. Statistical analysis: Kerti and Chang. Administrative, technical, or material support: Murugan and Kerti. Study supervision: Murugan.

\section{Availability of Data and Material}

The datasets used and/or analyzed during the current study are available from the corresponding author on reasonable request.

\section{Trial Registration}

The RENAL trial was registered on ClinicalTrials.gov (NCT00221013).

\section{References}

1 Alwall N. On the artificial kidney; apparatus for dialysis of the blood in vivo. Acta Med Scand. 1947 Aug 1;128(4):317-25.

2 Kidney Disease Improving Global Outcomes (KDIGO) Workgroup. Clinical practice guideline for acute kidney injury. Kidney Int Suppl. 2012;2:1-138.

3 Rosner MH, Ostermann M, Murugan R, Prowle JR, Ronco C, Kellum JA, et al. Indications and management of mechanical fluid removal in critical illness. Br J Anaesth. 2014 Nov;113(5):764-71.

4 Mehta RL, Pascual MT, Soroko S, Chertow GM, Group PS. Diuretics, mortality, and nonrecovery of renal function in acute renal failure. JAMA. 2002 Nov 27;288(20):2547-53.

5 RENAL Replacement Therapy Study Investigators; Bellomo R, Cass A, Cole L, Finfer S, Gallagher M, et al. An observational study fluid balance and patient outcomes in the randomized evaluation of normal vs. augmented level of replacement therapy trial. Crit Care Med. 2012 Jun;40(6):1753-60.

6 Hall A, Crichton S, Dixon A, Skorniakov I, Kellum JA, Ostermann M. Fluid removal associates with better outcomes in critically ill patients receiving continuous renal replacement therapy: a cohort study. Crit Care. 2020 Jun 1;24(1):279.

7 Murugan R, Kerti SJ, Chang CH, Gallagher M, Clermont G, Palevsky PM, et al. Association of net ultrafiltration rate with mortality among critically ill adults with acute kidney injury receiving continuous venovenous hemodiafiltration: a secondary analysis of the Randomized Evaluation of Normal vs Augmented Level (RENAL) of renal replacement therapy trial. JAMA Netw Open. 2019 Jun 5; 2(6):e195418.

8 Naorungroj T, Neto AS, Zwakman-Hessels L, Yanase F, Eastwood G, Murugan R, et al. Early net ultrafiltration rate and mortality in critically ill patients receiving continuous renal replacement therapy. Nephrol Dial Transplant. 2020 Apr 7:1-8.

9 Prowle JR, Echeverri JE, Ligabo EV, Ronco C, Bellomo R. Fluid balance and acute kidney injury. Nat Rev Nephrol. 2010 Feb;6(2):107-15.

10 Heung M, Wolfgram DF, Kommareddi M, $\mathrm{Hu}$ Y, Song PX, Ojo AO. Fluid overload at initiation of renal replacement therapy is associated with lack of renal recovery in patients with acute kidney injury. Nephrol Dial Transplant. 2012 Mar;27(3):956-61.

11 Prowle JR, Kirwan CJ, Bellomo R. Fluid management for the prevention and attenuation of acute kidney injury. Nat Rev Nephrol. 2014 Jan;10(1):37-47.

12 Silversides JA, Pinto R, Kuint R, Wald R, Hladunewich MA, Lapinsky SE, et al. Fluid balance, intradialytic hypotension, and outcomes in critically ill patients undergoing renal replacement therapy: a cohort study. Crit Care. 2014 Nov 18;18(6):624.

13 Marants R, Qirjazi E, Grant CJ, Lee TY, McIntyre CW. Renal perfusion during hemodi- alysis: intradialytic blood flow decline and effects of dialysate cooling. J Am Soc Nephrol. 2019 Jun;30(6): 1086-95.

14 Lee Y, Okuda Y, Sy J, Kim SR, Obi Y, Kovesdy $\mathrm{CP}$, et al. Ultrafiltration rate effects declines in residual kidney function in hemodialysis patients. Am J Nephrol. 2019 Oct 29;50(6):4818.

15 Gleeson PJC IA, Sexton DJ, Fontana V, Taccone F, Creteur J, Vincent JL. Determinants of renal recovery and mortality in patients undergoing continuous renal replacement therapy in the ICU. Intensive Care Med Exp. 2015; 3(Suppl 1):A54.

16 Pajewski R, Gipson P, Heung M. Predictors of post-hospitalization recovery of renal function among patients with acute kidney injury requiring dialysis. Hemodial Int. 2018 Jan; 22(1):66-73

17 Gooley TA, Leisenring W, Crowley J, Storer BE. Estimation of failure probabilities in the presence of competing risks: new representations of old estimators. Stat Med. 1999 Mar 30;18(6):695-706.

18 Berry SD, Ngo L, Samelson EJ, Kiel DP. Competing risk of death: an important consideration in studies of older adults. J Am Geriatr Soc. 2010 Apr;58(4):783-7.

19 Noordzij M, Leffondré K, van Stralen KJ, Zoccali C, Dekker FW, Jager KJ. When do we need competing risks methods for survival analysis in nephrology? Nephrol Dial Transplant. 2013 Nov;28(11):2670-7. 
20 Kalbfleisch JD, Prentice RL. Estimation of the average hazard ratio. Biometrika. 1981;68(1): 105-12.

21 RENAL Replacement Therapy Study Investigators; Bellomo R, Cass A, Cole L, Finfer S, Gallagher $\mathrm{M}$, et al. Intensity of continuous renal-replacement therapy in critically ill patients. N Engl J Med. 2009 Oct 22;361(17): 1627-38.

22 von Elm E, Altman DG, Egger M, Pocock SJ, Gøtzsche PC, Vandenbroucke JP, et al. The Strengthening the Reporting of Observational Studies in Epidemiology (STROBE) statement: guidelines for reporting observational studies. Ann Intern Med. 2007 Oct 16;147(8): 573-7.

23 Murugan R, Balakumar V, Kerti SJ, Priyanka $\mathrm{P}$, Chang $\mathrm{CH}$, Clermont $\mathrm{G}$, et al. Net ultrafiltration intensity and mortality in critically ill patients with fluid overload. Crit Care. 2018 Sep 24;22(1):223.

24 Serpa Neto A, Naorungroj T, Murugan R, Kellum JA, Gallagher M, Bellomo R. Heterogeneity of effect of net ultrafiltration rate among critically Ill adults receiving continuous renal replacement therapy. Blood Purif. 2020 Oct 7:1-11.

25 Naorungroj T, Serpa Neto A, Murugan R, Kellum JA, Bellomo R. Continuous renal replacement therapy: the interaction between fluid balance and net ultrafiltration. Am J Respir Crit Care Med. 2021 Jan 29.

26 Psaty BM, Koepsell TD, Lin D, Weiss NS, Siscovick DS, Rosendaal FR, et al. Assessment and control for confounding by indication in observational studies. J Am Geriatr Soc. 1999 Jun;47(6):749-54.

27 Lederer DJ, Bell SC, Branson RD, Chalmers JD, Marshall R, Maslove DM, et al. Control of Confounding and Reporting of Results in Causal Inference Studies. Guidance for authors from editors of Respiratory, Sleep, and Critical Care Journals. Ann Am Thorac Soc. 2019 Jan;16(1):22-8.

28 Bouchard J, Soroko SB, Chertow GM, Himmelfarb J, Ikizler TA, Paganini EP, et al. Fluid accumulation, survival and recovery of kidney function in critically ill patients with acute kidney injury. Kidney Int. 2009 Aug;76(4): 422-7.

29 Buuren SV, Groothuis-Oudshoorn K. MICE: multivariate imputation by chained equations in R. J Stat Softw. 2011;45(3):1-67.

30 Siew ED, Peterson JF, Eden SK, Moons KG, Ikizler TA, Matheny ME. Use of multiple imputation method to improve estimation of missing baseline serum creatinine in acute kidney injury research. Clin J Am Soc Nephrol. 2013 Jan;8(1):10-8
31 Zavada J, Hoste E, Cartin-Ceba R, Calzavacca $\mathrm{P}$, Gajic O, Clermont G, et al. A comparison of three methods to estimate baseline creatinine for RIFLE classification. Nephrol Dial Transplant. 2010 Dec;25(12):3911-8.

32 Pepe MS, Mori M. Kaplan-Meier, marginal or conditional probability curves in summarizing competing risks failure time data? Stat Med. 1993 Apr 30;12(8):737-51.

33 Lau B, Cole SR, Gange SJ. Competing risk regression models for epidemiologic data. Am J Epidemiol. 2009 Jul 15;170(2):244-56.

34 Andersen PK, Geskus RB, de Witte T, Putter $\mathrm{H}$. Competing risks in epidemiology: possibilities and pitfalls. Int J Epidemiol. 2012 Jun; 41(3):861-70

35 Putter H, Fiocco M, Geskus RB. Tutorial in biostatistics: competing risks and multi-state models. Stat Med. 2007 May 20;26(11):2389_ 430.

36 Fine JP, Gray RJ. A proportional hazards model for the subdistribution of a competing risk. J Am Stat Assoc. 1999 Jun;94(446):496509.

37 Wulfsohn MS, Tsiatis AA. A joint model for survival and longitudinal data measured with error. Biometrics. 1997 Mar;53(1):330-9.

38 Rizopoulos D. Dynamic predictions and prospective accuracy in joint models for longitudinal and time-to-event data. Biometrics. 2011 Sep;67(3):819-29.

39 Vaara ST, Korhonen AM, Kaukonen KM, Nisula S, Inkinen O, Hoppu S, et al. Fluid overload is associated with an increased risk for 90-day mortality in critically ill patients with renal replacement therapy: data from the prospective FINNAKI study. Crit Care. 2012 Oct 17;16(5):R197.

40 Balakumar V, Murugan R, Sileanu FE, Palevsky P, Clermont G, Kellum JA. Both positive and negative fluid balance may be associated with reduced long-term survival in the critically ill. Crit Care Med. 2017 Aug;45(8): e749-57.

41 Murugan R, Bellomo R, Palevsky PM, Kellum JA. Ultrafiltration in critically ill patients treated with kidney replacement therapy. Nature Rev Nephrol. 2020. 2020 Nov 11.

42 Naorungroj T, Neto AS, Zwakman-Hessels L, Fumitaka Y, Eastwood G, Murugan R, et al. Mediators of the impact of hourly net ultrafiltration rate on mortality in critically ill patients receiving continuous renal replacement therapy. Crit Care Med. 2020 Oct;48(10): e934-42.

43 Bos WJ, Bruin S, van Olden RW, Keur I, Wesseling KH, Westerhof N, et al. Cardiac and hemodynamic effects of hemodialysis and ultrafiltration. Am J Kidney Dis. 2000 May;35(5): 819-26.
44 Buchanan C, Mohammed A, Cox E, Köhler K, Canaud B, Taal MW, et al. Intradialytic cardiac magnetic resonance imaging to assess cardiovascular responses in a short-term trial of hemodiafiltration and hemodialysis. J Am Soc Nephrol. 2017 Apr;28(4):1269-77.

45 Eldehni MT, McIntyre CW. Are there neurological consequences of recurrent intradialytic hypotension? Semin Dial. 2012 May;25(3): 253-6.

46 McIntyre CW, Harrison LE, Eldehni MT, Jefferies HJ, Szeto CC, John SG, et al. Circulating endotoxemia: a novel factor in systemic inflammation and cardiovascular disease in chronic kidney disease. Clin J Am Soc Nephrol. 2011 Jan;6(1):133-41.

47 Saran R, Bragg-Gresham JL, Levin NW, Twardowski ZJ, Wizemann V, Saito A, et al. Longer treatment time and slower ultrafiltration in hemodialysis: associations with reduced mortality in the DOPPS. Kidney Int. 2006 Apr;69(7):1222-8.

48 Movilli E, Gaggia P, Zubani R, Camerini C Vizzardi V, Parrinello G, et al. Association between high ultrafiltration rates and mortality in uraemic patients on regular haemodialysis. A 5-year prospective observational multicentre study. Nephrol Dial Transplant. 2007 Dec; 22(12):3547-52.

49 Flythe JE, Kimmel SE, Brunelli SM. Rapid fluid removal during dialysis is associated with cardiovascular morbidity and mortality. Kidney Int. 2011 Jan;79(2):250-7.

50 Flythe JE, Curhan GC, Brunelli SM. Disentangling the ultrafiltration rate-mortality association: the respective roles of session length and weight gain. Clin J Am Soc Nephrol. 2013 Jul;8(7):1151-61

51 Lysaght MJ, Vonesh EF, Gotch F, Ibels L, Keen M, Lindholm B, et al. The influence of dialysis treatment modality on the decline of remaining renal function. ASAIO Trans. 1991 Oct-Dec;37(4):598-604.

52 Moist LM, Port FK, Orzol SM, Young EW, Ostbye T, Wolfe RA, et al. Predictors of loss of residual renal function among new dialysis patients. J Am Soc Nephrol. 2000 Mar;11(3): 556-64.

53 Lumlertgul N, Murugan R, Seylanova N, McCready P, Ostermann M. Net ultrafiltration prescription survey in Europe. BMC Nephrol. 2020 Dec 1;21(1):522.

54 Murugan R, Ostermann M, Peng Z, Kitamura K, Fujitani S, Romagnoli S, et al. Net ultrafiltration prescription and practice among critically ill patients receiving renal replacement therapy: a multinational survey of critical care practitioners. Crit Care Med. 2020 Feb;48(2): e87-97.
Net Ultrafiltration Rate and Renal Recovery
Blood Purif 2022:51:397-409 